University of Nebraska - Lincoln DigitalCommons@University of Nebraska - Lincoln

To Improve the Academy

Professional and Organizational Development

Network in Higher Education

1992

Breaking Barriers: Mentoring Junior Faculty

Women for Professional Development and

Retention

Marie A. Wunsch

Linda K. Johnsrud

Follow this and additional works at: http://digitalcommons.unl.edu/podimproveacad

Part of the Higher Education Administration Commons

Wunsch, Marie A. and Johnsrud, Linda K., "Breaking Barriers: Mentoring Junior Faculty Women for Professional Development and Retention" (1992). To Improve the Academy. 269.

http://digitalcommons.unl.edu/podimproveacad/269

This Article is brought to you for free and open access by the Professional and Organizational Development Network in Higher Education at DigitalCommons@University of Nebraska - Lincoln. It has been accepted for inclusion in To Improve the Academy by an authorized administrator of DigitalCommons@University of Nebraska - Lincoln. 


\section{Breaking Barriers: Mentoring Junior Faculty Women for Professional Development and Retention}

\section{Marie A. Wunsch}

University of Hawaii

\section{Linda K. Johnsrud}

University of Hawaii

This paper describes a successful two-year pilot program on mentoring new junior faculty women. The program emphasizes individual professional development and retention issues and includes colleague-pairing, mentor training, the use of a mentoring agreement, and a multi-leveled series of development workshops, seminars, and networking activities. The assessment and research component includes a needs assessment, pre-and postparticipation perception studies, assessment interviews, and a proposed longitudinal study of mentees from entrance to tenure.

A decade ago a major problem facing women planning academic careers was lack of full access to graduate programs and then to faculty positions in colleges and universities. In the student ranks, women are now the majority of undergraduate students in higher education, and there is a significant increase in women earning doctorates in a broader number of fields. In the faculty ranks, national data project a shortage of qualified faculty for the positions that will be available in colleges and universities in the late 1990's (Bowen \& Schuster, 1986; El-Khawas, 1989). The major challenge for higher education, then, will be the full utilization of women prepared to assume 
academic positions. Already there is a noticeable increase in institutional programs to recruit, compensate, retain, and tenure new faculty.

Efforts to retain are critical because, as findings indicate, women are more likely than their male peers to leave academic institutions prior to tenure decisions (Finkelstein, 1984; Johnsrud \& Atwater, 1991a; Lovano-Kerr, \& Fuchs, 1983; Menges \& Exum, 1983). Moreover, when competitive recruitment offers are made to junior faculty to leave their current positions, evidence from at least one institution indicates that males, more often than women, receive counter offers in salary and benefits to stay at their home institutions (Arizona Board of Regents, 1991). Such patterns of attrition and retention must be reversed if faculty women are to achieve parity in representation.

Excluding the salary issue, which is the most frequently cited difference for men and women across all ranks (Leatherman, 1991, p. A14), the major hindrance to women's success seems to be the lack of a supportive, even hospitable, climate. Faculty women report greater intellectual and social isolation (Johnsrud \& Atwater, 1991a; Yoder, 1985). They are more likely to have their scholarship discredited (Kritek, 1984), although women publish as much as their male peers in refereed journals (Astin, Korn, \& Dey, 1991). Faculty women have greater difficulty obtaining resources to support scholarly activities required for tenure and promotion, such as professional travel funds, research monies, equipment for laboratories and released time for research activities (Carnegie Foundation for the Advancement of Teaching, 1989; Finkelstein, 1984). Female assistant professors often have heavier teaching loads, more students in large undergraduate classes, and more departmental committee assignments. Although women are good campus citizens, such citizenship is less valued for advancement than traditional research and publication (Carnegie Foundation for the Advancement of Teaching, 1990). Over 50\% of women in public universities (but no men) report subtle discrimination as a source of job stress. Only $33 \%$ of the women conclude that they still want to be college professors as opposed to $43 \%$ of the men (Astin, Korn, \& Dey, 1991).

Furthermore, scholarship on women's careers provides evidence that success often depends not only on one's knowledge but on one's contacts, not only on hard work but on the ability to self-promote, and not only on technical competence but on the confidence to pursue the highest aspirations. Adelman (1991) reports on an extensive national longitudinal study of the careers and labor market experiences of the high school class of 1972 $(\mathrm{N}=22,652)$ to the age of thirty-two. Women's achievements are superior to those of men (SAT scores, GPA, college grades, number of years of training, 
satisfaction with education). The paradox is that their rewards, status and advancement in the labor market are thin when compared to men. A notable observation is that women come to careers determined to succeed on the basis of what they know, not whom they know. Even though this determination may contribute to their productivity, they often get stuck or encapsulated in ways that hinder their effectiveness and advancement. Similarly, success in the academic marketplace requires a high level of educational attainment, but moving through the system of rewards and status requires knowing colleagues who can provide the guidance, support, and astute insight into the political processes of the institution.

Scholars and researchers flourish more rapidly if they receive clear expectations about success and encouragement that endorses intellectual strengths and career commitments (Astin \& Leland,1991). In academe, however, males have more natural access to this kind of collegial guidance than females. McClosky (1991) clarifies the dilemma of what has become known as the "invisible college." Highly entrenched in the sciences, but developing increasingly in other disciplines, is the network of established experts who come to govern their disciplines by influencing hiring, publications, and promotions beyond the power of the campus colleagues. Few faculty are tenured without "outside evaluators" of their professional work. Women, as yet, do not constitute a strong part of this network. However, their work will likely be judged by the network if their own colleagues value what is being promulgated by "the invisibles."

When women faculty are also members of an ethnic minority, their opportunities for access to this network through informal means is even more limited (Hall \& Sandler, 1983). Clearly, retaining faculty women and developing an equitable institutional climate and support system are closely linked. Mentoring is an emergent strategy to meet the needs of both individual faculty development and the redirection of the institutional support system.

\section{Mentoring as a Retention Strategy}

Like its origins in mythology, mentoring has elusive definitions and functions. Mentor in The Odyssey, was the patron, advisor, guide, role model, teacher, and inspirer of the young Prince Telemachus' rites of passage into Greek manhood; it may be instructive to remember that Mentor was a disguise of Athena, the goddess of wisdom. Can we then say that mentoring is a wise way of imparting knowledge, a wise way of using the wisdom of tradition, and a wise way of using the experiences of established colleagues on behalf of those gaining passage into academe? One wonders about the 
outcome of Athena's mentoring had she chosen, instead, the Princess Nausica to develop.

Although mentoring is not new, either in the corporate sector to develop professionals or in academe to retain students, few formal programs for mentoring junior academics have been developed and assessed. No doubt a good deal of informal helping among faculty does occur, but to be effective in the long-term, mentoring cannot be viewed as a peripheral or compensatory program for women only. Rather it must be viewed as a strategy for changes in the structure and climate of the institution.

The following discussion highlights a successful two-year pilot program at the University of Hawaii for systematic mentoring of junior faculty women. The goals of the program are to develop the academic careers of junior faculty women and to ensure institutional change through the retention of women faculty. The activities of the program are multi-leveled to meet the complex interests and needs of women in a variety of disciplines during their early years at the university.

\section{The Mentoring Program at the University of Hawaii}

Mentoring programs have the highest chance for impact if they are created in response to needs identified by the participants and congruent with the goals of the institution. Studies gathering data on the barriers to the advancement of women or on the climate for women are not routine on most campuses, but are usually conducted when gender, equity, climate, and retention issues for women become vocalized concerns. (In the past five years, for example, the University of Maryland, University of Wisconsin, Ohio State University, University of Kentucky, and University of Arizona, among others, have released major reports). Academics rarely consider credible anecdotal material on women's experiences, unless it is documented by traditional research methods. Grounding a mentoring program in data provides information not only for planning and implementation of a program but also for establishing a mechanism for clear assessment of outcomes. Thus, the mentoring program at the University of Hawaii began with considerable attention to available data as well as a needs assessment.

\section{Data Gathering and Analysis}

A University of Hawaii study on Barriers to Retention and Tenure: The Experiences of Faculty Cohorts, 1982-88 (Johnsrud \& Atwater, 1991a) informed the evolution of the mentoring program. The study included 325 
faculty who entered tenure track positions, including 93 who left the institution, 127 who were still probationers, and 105 who had received tenure. Results indicated that women experienced their academic careers differently than did their male peers. Women in the study left their tenure track positions at a rate significantly higher than men (women comprised $34.1 \%$ of the population, but $45.2 \%$ of the leavers). The common threads of women's experience did not differ markedly from those reported in other recent national studies (Astin, Korn \& Dey, 1991; Carnegie Foundation for the Advancement of Teaching, 1989). Women faculty reported greater lack of institutional resources and support, isolation, tenure pressures, workload imbalance, stressful relations with colleagues and department chairs, and discrimination. The expressed need for mentoring was widespread.

In addition to the review of national and institutional data on the professional development needs of junior faculty women, additional planning studies provided insights for the program. A needs assessment was conducted during the summer with all senior faculty women (tenured associate and full professors) and with all probationary women (assistant professors), and with a cohort of new women entering the university in Fall, 1990. Junior women identified a variety of interests in the areas of career planning, teaching development, research support, dual career issues, orientation to a multicultural campus, and personal adjustment issues. Senior women identified areas in which they had experience solving problems and areas in which they had expertise or interest in mentoring. Respondents could also include lifestyle issues to facilitate colleague matching.

At the initiation of the program, another survey was conducted on the perceptions of the women in the colleague-pairing aspect of the program. The purpose was to explore empirically the perceptions of senior and junior women faculty regarding the barriers to success experienced in the early academic career. A factor analysis of the responses of twenty-two pairs was used to examine the differences between senior and junior women (Johnsrud $\&$ Wunsch, 1991a). At the end of the first year, a follow-up survey explored the differences before and after participation in the program. Results were used to structure appropriate activities for faculty women to help themselves and one another succeed in an academic setting (Johnsrud \& Wunsch,1991b).

\section{Program Placement and Resources}

The mentoring program was placed within the university's Office of Faculty Development and Academic Support. Because that office is charged with emphasizing development programs for all new faculty (new faculty orientation, teaching development seminars, workshops on institutional re- 
sources, travel monies, and curriculum development grants) for purposes of retention as well as professional growth, the mentoring program for junior women faculty was a natural addition. Placing responsibility for the program with a senior administrator in an established program for serving faculty signalled that mentoring is not an expedient add-on in times of crisis, but part of an integrated effort to retain new faculty. The program was named one of the President's initiatives, ensuring further visibility and resources, and was supported by an initial $\$ 10,000$ grant to cover staff support, materials, and small stipends for the mentors. The continuation of the program is now enhanced by its being included in crucial planning documents such as the campus academic development plan and the affirmative action plan and in budget documents.

\section{Program Characteristics}

Within this program, mentoring is considered to be a long-range career development strategy, so that all activities are directed toward fostering career growth from the time a woman faculty member enters the institution through tenure and promotion. The first year mentoring activities encourage the probationary woman to understand the academic culture of the campus, to identify and use resources to support teaching and research activities, to develop networks of senior and junior colleagues to facilitate professional work, and to learn the particular social and political dynamics of the home department. At this time only senior faculty women have been asked to serve as mentors on the assumption that they can more effectively facilitate the networking of women faculty, provide role models for successful careers, and convey the lessons of the "survivors" experiences. The program is characterized by an emphasis on three main areas.

1. Entry level survival needs in the institution. Although each academic department has a particular socio-political culture with its own implicit and explicit policies, procedures, and interpersonal expectations, the university as a whole also has culture that will affect the academic career. New faculty require access to this information to function as accepted peers and professionals. Mentors can provide institutional information on services, benefits, intramural monies for teaching, travel, or research, act as advocates for the newcomers, and help them to integrate into the scholarly community of the institution. For this reason, newcomers are paired with a mentor from outside the home department, but in a cognate discipline or from the same college, who has extensive knowledge of the campus routines and rituals.

2. Career development and advancement needs. As a faculty member progresses through the initial career stages, there are more particular skills, 
bodies of knowledge, and contributions expected to attain tenure and promotion. In the press of first year orientation and adjustment, new faculty members seldom see themselves planning an academic career. Yet, most institutions almost immediately require some assessment for contract renewal, and the results begin to affect retention decisions on each side. Mentors must make a special point of advising mentees of the importance of understanding review criteria and the evaluation process early in the first year. Data such as student and peer evaluations, research proposals, and letters of support need to be acquired early for constructing the history of achievement necessary for the tenure dossier later.

3. Socio-psychological needs. All faculty should expect a campus climate that offers full collegiality and respect for individuality. Since "the faculty" is neither a collective entity nor a monolithic group, each individual requires a balance of competencies to deal with colleague communication and interactions. The intrinsic motivators and rewards most appealing to faculty are, in great measure, those of affiliation, competence, mutual respect and peer recognition, and support (Bowen \& Schuster, 1986). Multiple studies of women's experiences (Carnegie Foundation for the Advancement of Teaching, 1990; Finkelstein, 1984; Kritek, 1984) conclude, however, that such rewards are not easily attained by women faculty. Mentors can serve as guides and models in helping to develop the skills needed to cope with less -than-congenial relationships, as well as in suggesting ways to influence the climate of the department so that women are included and respected as colleagues.

\section{Program Activities}

In the initial years of the program, colleagues were paired by the program advisory committee on the basis of information supplied about career needs in the initial assessment survey. If voluntary data were included on lifestyle issues, every attempt was made to match women with similar backgrounds and family situations (e. g., dual career couples or mothers of small children). All mentors were senior, tenured women faculty, and each was from a related discipline outside the mentees' home department. Women were matched on the assumption that the first phase of mentoring for those new to the institution involved orientation to the general culture of the university, to available resources for professional development, to available services on the campus and in the community, to a network of other new women in various disciplines, and to a group of experienced women faculty. Pairing outside the home department provided more neutral advisors while the new faculty members were gaining insight into the politics and practices of the 
department. Outside mentors were often able to be objective advocates for the new women with senior colleagues or the department chair in a way that might not have been possible by women within the department.

During the first year there were thirty-four colleague pairs from twentyseven different departments. Of these pairs, twenty-nine mentees were in their initial year of hire and the other five were in their second or third year. An exception was made for the five because they were the only women in their departments. Only two pairs chose not to continue in the program; one pair with initial difficulties was successfully reassigned. Particular attention was given to pairing new women who were the first or only females in their departments. Two such women in the natural sciences had two mentors to ensure additional advice on grant and research development, matters of particular concern in the sciences. Mentees were also encouraged to identify other mentors, male or female, within their own departments to work on more specific aspects of colleague relations and expectations in the department.

In the second year another eighteen pairs were added. Simultaneously, mentoring groups were set up to accommodate women faculty whose primary responsibilities were other than teaching and research (i. e., librarians, student support specialists, non-tenure track foreign language instructors). In this model, mentors and mentees worked together in groups and evolved a general agreement on the areas in which they wished to focus their discussions and activities.

Mentor training and meetings. A number of mentors expressed concern about their ability to carry on a mentoring relationship and about the elusiveness of the process itself. Many had not had mentors themselves or had never engaged in mentoring activities. Others were uneasy about structuring a process that they felt was personal and informal. Thus, mentors agreed to meet once a month as a group with the program coordinator to discuss the mentoring process, to identify resources or persons to support their mentees, and to identify common professional or institutional problems encountered by new faculty. The program coordinator contributed articles and research on mentoring as well as information on institutional resources that supported mentoring. During the meetings a mentor could introduce a "critical incident" and ask for suggestions from other mentors or report on a positive helping activity. An assessment of the first year program (survey and interviews) showed that the mentors thought that structure helped considerably to focus the activities. The mentors reported benefiting from interaction with other senior colleagues, some of whom had not met before the program (Johnsrud \& Atwater, 1991b).

Mentee group meetings. The mentees also met once a month as a group 
with the program coordinator to analyze their own experiences, to develop personal contacts and professional relationships within the cohort, to identify common problems, and to detail actual strategies used to address critical issues. Close association with a peer cohort proved very productive for confirming the common adjustment patterns of new faculty and for easing some of the isolation and stress of "going it alone" as the newcomer. Some groups formed research and writing collaborations, and some single women planned social activities. In the second year, a group of minority women in the program formed a focus group to meet separately on occasion to discuss what they believed to be unique about their experiences.

The mentoring agreement. Each colleague pair agreed to complete a written agreement whereby they detailed how often they would meet and what specific activities they would pursue based on the interests and needs of the mentee. The written agreement was designed to be a tool for two persons who did not know one another to begin the process of developing a working relationship quickly. Discussing specific professional development issues forced the junior colleague to conceptualize and detail her own career needs and to identify strategies to address those needs. Retention decisions on the part of junior faculty women depended on how quickly they were able to progress toward their own goals. Focus on specific goals allowed for both immediate and long range accomplishment, particularly in learning to negotiate the system. The only requirement was that a plan be developed by mutual agreement of the pair; otherwise they were free to make individual decisions on time commitments and the number and kinds of activities they choose.

The agreements varied considerably in form, ranging from a detailed weekly work log to a creative "fable" about the elements of developing a female academic. What may have appeared to be a rigid requirement proved to be as diverse and rich as the participants themselves. Those who established clear objectives and maintained the time commitment to meet regularly reported the most productive and personally satisfying experiences. Half the group met at least once a month, and the other half met about twice a month. Over half also kept in touch by telephone and electronic mail or met to participate in a professional or social activity in addition to their mentoring meeting. An analysis of the mentoring agreements proved invaluable in identifying common areas of concern and experience that cut across the participants. A list of activities and strategies shared with those coming into the program the second year served as a quick start for their plans.

Monthly seminars on career development. Topics of common interest that could be handled more effectively in a group format became the basis 
for two-hour seminars presented by individual experts or panels of women faculty. The advantage of this open format was that all women on campus could be invited, not only those in the mentoring program. Some topics addressed included using academic writing groups, planning for tenure from the first year, managing time and balancing priorities, developing a scholarly agenda, and securing intramural funds for research, travel, and career development. Mentors frequently came to these sessions with the mentees, thus providing a richer mix of expertise to supplement that of the presenters.

Informal social activities. Because many junior faculty report social and intellectual isolation and difficulty meeting faculty from other departments, a series of informal social events were offered to women faculty. There was a luncheon in an executive dining room on campus to open the year's program, followed by monthly brown bag lunches open to all faculty women. These activities provided opportunities for the women to develop relationships on a more personal basis and in a relaxed environment. In the planning stage are a series of lunches on site in different departments, laboratories, and research areas to acquaint participants with the range of work in which women faculty are involved on a large, decentralized campus.

Evaluation. If personal and organizational change is a goal, a program must be prepared to supply evidence of impact. Therefore, an evaluation for the program was conducted at the end of the first year. An open-ended interview guide was developed to elicit comments about each individual's experience in the mentor-mentee relationship and the program in general, including suggestions for change. One-to-one interviews were audio-taped for 51 of the women who participated in the first year of the program. Analysis of the transcribed interviews indicated that the support for the mentoring program by all participants interviewed was overwhelmingly positive. Even in the few cases in which the individuals had less than satisfactory personal relationships with their particular mentor or mentee, they expressed strong support for the program as a whole.

Relationships were seen as most helpful in the areas of departmental and institutional politics, and the tenure process. Generally, respondents perceived that relationships worked well when the mentor served as an active listener to facilitate the mentee's own problem solving abilities, offered emotional support and encouragement in professional and personal matters, and suggested strategies for dealing with department relations and the tenure clock. Specifically, mentors whose discipline or college was sufficiently distant from that of their mentee were able to provide a new perspective of institutional politics and procedures that helped extend the mentee's view and understanding of the institution. The mentoring relationship was also 
seen as helpful in dealing with problematic features of the tenure clock, particularly in the balancing of teaching, research, and service.

Because the assumption in these pairings was that the mentor was helping the mentee, the most successful relationships resulted when the mentor actively took the initiative in making contact. The typical mentee hesitated about initiating contact because she perceived her mentor to be overworked and thus did not want to be a burden.

Some notes of caution were expressed. First, concern was voiced that the program not become too institutionalized or bureaucratic. Participants felt that the nature of mentoring is so personal and idiosyncratic that the organized program should be loosely structured. Second, it was felt that critical attention must be paid to the matching of senior and junior women. It appears that matches too close (within the same department) or too distant (completely unrelated disciplines) are not as successful as matches in which the individuals have some degree of intellectual and/or personal overlap of interests. Finally, because the community of women faculty is relatively small, respondents raised the issue of confidentiality as an area of concern.

The assessment of the first year of the mentoring program proved to be useful for immediate program planning and training as well for the long-term development of the program. A long-range assessment mechanism will consist of a longitudinal study of the cohorts as they proceed from entrance into the university through the completion of the tenure process. A series of individual interviews will be conducted to identify changes in the needs and perceptions of participants as they move through the tenure process.

\section{Conclusion}

Concern about the recruitment and retention of women faculty must be transformed into action. A combination of strategies must be brought to bear to reach the level of success envisioned by enlightened colleges and universities. Progress requires serious affirmative action efforts to enhance recruitment as well as campus programs that show institutional support for new faculty and a commitment to their professional development. A successful mentoring program that promises information about advancing within the institution and provides a supportive network of senior colleagues can be part of an effective recruitment package. Women faculty who experience immediate attention to their adjustment and professional growth are more likely to want to stay after they are hired. To be effective, a mentoring program must meet the needs of individual faculty women, but also be a part of the general support system. A effective program has visibility, administrative support, and just enough structure to facilitate worthwhile activities and to motivate 
participants to spend valuable time with one another. An effective program needs sufficient data to facilitate program planning and assessment, to justify its continuation, and to provide evidence that it can, even in the short run, accomplish the goals of developing and retaining qualified faculty women.

\section{References}

Adelman, C. (1991). Women at thirty something: Paradoxes of attainment. Washington, D.C.: Department of Education, Office of Educational Research and Improvement.

Arizona Board of Regents. (1991). Reaching the vision: Women in Arizona's universities in the year 2000. Arizona Board of Regents, Commission on the Status of Women.

Astin, A. W., Korn, W. S., \& Dey, E. L. (1991). The American college teacher. Los Angeles, CA.: Higher Education Research Institute, University of California, Los Angeles.

Astin, H. S., \& Leland, C. (1991). Women of influence, women of vision: A cross-generational study of leaders and social change. San Francisco, CA.: Jossey-Bass.

Bowen, W. G., \& Schuster, J. H. (1986). American professors: A national resource imperiled. New York.: Oxford University Press.

Carnegie Foundation for the Advancement of Teaching. (1990). Women faculty excel as campus citizens. Change, 22, 39-43.

Carnegie Foundation for the Advancement of Teaching (1989). The Condition of the Professoriate. Princeton, NJ.: Carnegie Foundation.

El-Khawas, E. (1989). Campus trends: Higher education reports, 1989. Washington, D.C.: American Council on Education.

Finkelstein, M. (1984) The American academic profession: A synthesis of social scientific inquiry since World War II. Columbus, $\mathrm{OH}$ : Ohio State University Press.

Hall, R. M., \& Sandler, B. R. (1983). Academic mentoring for women students and faculty: A new look at an odd way to get ahead. Washington, D.C.: Association of American Colleges.

Johnsrud, L. K., \& Atwater, C. D. (1991a). Barriers to retention and tenure at UH-Manoa: Faculty cohorts 1982-1988. Technical Report. University of Hawaii: Honolulu, Hawaii.

Johnsrud, L. K., \& Atwater, C. D. (1991b). Women faculty mentoring program assessment 1990-91. In the Report on the educational improvement fund 1990-91, (pp. 139-144). University of Hawaii at Manoa: Office of Faculty Development and Academic Support.

Johnsrud, L. K., \& Wunsch, M. A. (1991a). Junior and senior faculty women: Commonalties and differences in perceptions of academic life. Psychological Reports, 69, 879-886.

Johnsrud, L.K., \& Wunsch, M.A. (1991b). Barriers to success in academic life: Perceptions of faculty women in a colleague pairing program. Paper presented at the annual meeting of the Association for the Study of Higher Education, Boston.

Kritek, P. (1984). Women's work and academic sexism. Educational Record, 65, 56-57.

Leatherman, C. (1991, April 3). Professors' salaries fail to keep pace with cost of living. Chronicle of Higher Education, 37(29), A1, A14-A18. 
Lovano-Kerr, J., \& Fuchs, R. G. (1983). Retention revisited: A study of female and male nontenured faculty. Journal of Educational Equity and Leadership, 3, 219-230.

McClosky, D. N. (1991). Invisible colleges and economics: An unacknowledged crisis in academic life. Change, 23, 21-26.

Menges, R. J., \& Exum, W. H. (1983). Barriers to the progress of women and minority faculty. Journal of Higher Education, 54, 123-143.

Yoder, J. D. (1985) An academic woman as token: A case study. Journal of Social Issues, 41, 61-72. 